\title{
Paradojas de la innovación y la migración calificada de inventores en el contexto neoliberal: reflexiones en torno al caso mexicano
}

\author{
Paradoxes of innovation and the skilled migration of inventors \\ in the neoliberal context: reflections on the case of Mexico
}

Selene Gaspar Olvera*

ISSN IMPRESO 1870-7599 | ISSN RED CÓMPUTO 2448-7783 | 143-175

RECIBIDO 01/06/21 | ACEPTADO 10/06/21

\begin{abstract}
Resumen. El nexo entre desarrollo científico y tecnológico e innovación es indiscutible en el mundo contemporáneo; igual de relevante es la relación entre el gasto público y privado y el grado de patentamiento. En el periodo neoliberal, que data de hace casi 40 años, la sostenida reducción del gasto público en los países periféricos en general y en México en lo particular explica el por qué la innovación y el patentamiento se han reducido de manera sostenida para afianzar el proceso de acumulación en los países centrales. El propósito de la presente investigación es evidenciar la forma en la que al amparo de los procesos de recesión y crisis permanente, la migración altamente calificada alimenta los procesos de acumulación en el Centro y genera una dinámica profundamente paradójica: la fuerza de trabajo altamente calificada en la figura de los inventores de la periferia nutre las innovaciones de los países centrales que la venden o licencian, por la vía de las patentes, a los creadores de las ideas, hecho que propicia una dinámica de intercambio desigual que se agudiza y retroalimenta.
\end{abstract}

Palabras clave: innovación, patentes, migración calificada, neoliberalismo, México.

\begin{abstract}
The nexus between scientific and technological development and innovation is indisputable in the present era; also notable is the relation between public and private expenditures and the extent of patenting. In the neoliberal period, which dates back almost 40 years, the steady reduction in public expenditures among countries on the periphery in general and in Mexico in particular explains why innovation and patenting has been continuously eroded, entrenching the process of accumulation in the core countries. The aim of this research is to demonstrate how the protection of ongoing processes of recession and crisis results in highly skilled migration feeding the processes of accumulation in the Core and creates a deeply paradoxical dynamic: the highly skilled labor force in the form of inventors on the periphery nurtures innovations in the central countries to which the creators of ideas are sold or licensed, through patents, resulting in a feedback dynamic of unequal exchange that continuously deepens.
\end{abstract}

Keywords: innovation, patents, skilled migration, neoliberalism, Mexico.

\footnotetext{
* México. Maestra en Demografía Social y Actuaria por la Universidad Nacional Autónoma de México. Investigadora en la Unidad Académica en Estudios del Desarrollo, Universidad Autónoma de Zacatecas, adscrita al proyecto Sistema de Información Sobre Migración y Desarrollo (SIMDE-UAZ). Correo-e: selene.gasparolvera@gmail. com; sgaspar@estudiosdeldesarrollo.net
} 


\section{Introducción}

Las grandes economías son cada vez más dependientes del conocimiento y la innovación extranjera, el papel de los inventores migrantes tiene una relevancia creciente en una economía global basada en el conocimiento. Las principales potencias capitalistas recurren a la atracción de personal altamente calificado, incluidos los tecnólogos y los científicos, a fin de ampliar su potencial en la generación de patentes y en la concesión de licencias tecnológicas que conducen a reforzar su capacidad económica, así como para apuntalar sus procesos de innovación tecnológica. Siguiendo a Carsten Fink (2013), los inventores son representativos dentro de las economías de los países avanzados en virtud de que crean conocimiento y con ello capacidad de liderazgo y crecimiento económico, al situarse a la vanguardia de la transformación tecnológica e industrial. Asimismo, se distinguen por la importancia que conceden a la fuerza de trabajo altamente capacitada reclutada por sus instituciones educativas y centros de investigación.

En opinión de Breschi, Lissoni y Tarasconi (2014) la migración y la innovación son dos fenómenos históricamente entrelazados. En la actualidad, el flujo masivo y creciente de científicos e ingenieros se ha convertido en un tema crucial concerniente al análisis del capitalismo contemporáneo. Señalan que aunque existen países que actúan como origen y destino de los migrantes altamente calificados y de los inventores, un reducido número de países avanzados como Estados Unidos, Reino Unido, Canadá y Australia concentran 70 por ciento de los migrantes altamente calificados y, más todavía, 50 por ciento de ese talento reside en Estados Unidos.

La Organización Mundial de la Propiedad Intelectual (OMPI) considera que la relación entre migración e innovación debiera figurar como un foco principal de investigación, pues los migrantes altamente calificados entre los que se encuentran los científicos y tecnólogos son clave para impulsar el desarrollo y la difusión del conocimiento. La búsqueda de talento innovador ha llevado a muchos países a debatir y reformar su política de inmigración con el propósito de aliviar la escasez de habilidades nacionales, fomentar la innovación y la competitividad, tal es el caso de Francia, Alemania y España (Ozden, 2017). Paralelamente, ello ha requerido de políticas de protección para la fuerza de trabajo altamente calificada y el apuntalamiento de figuras legales para la protección de la propiedad intelectual (e.g., figura de patentes, marcas, diseños y derechos de autor). El autor referido indica que los patrones actuales de migración de talentos son resultado 
de diversos factores: a) las estrategias de empresas y empleadores que buscan cubrir el talento escaso; b) gobiernos que intentan gestionar los flujos de talentos a través de políticas de atracción; c) individuos que pretenden mejores opciones dadas las limitaciones que se les imponen en sus países de origen.

En concreto, los inventores migrantes son muy productivos y pertenecen primordialmente a las áreas de ciencia, tecnología e ingeniería; además, facilitan la producción de conocimientos gracias a las fronteras y otorgan dinamismo a la ciencia y a la tecnología en los países receptores, sus beneficios económicos son grandes y persisten en el tiempo (Bahar, Choudhury y Rapoport, 2019).

Entre 1985-2019 se han emitido 48.9 millones de solicitudes de patentes a escala mundial, de las cuales 23.1 por ciento son de no residentes; de igual modo, se han otorgado más de 25 millones de patentes, 40.0 por ciento corresponde a inventores no residentes en el país de la oficina de aplicación; esa transferencia de patentes ha favorecido para que los países de origen y destino formulen lineamientos y tratados que protejan a sus inventores e invenciones.

Con respecto al problema de la protección de patentes se han adoptado y establecido sistemas de protección de derechos de propiedad intelectual a escala nacional e internacional. La OMPI ofrece servicios que permitan proteger invenciones, marcas y diseños en múltiples países, por medio de WIPO-PCT para el Sistema Internacional de Patentes, WIPO-Madrid para el Sistema Internacional de Marcas y WIPO-Hague para el Sistema Internacional de Diseños. También se ha abogado por la flexibilidad de los sistemas de patentes, es decir, por la capacidad de maniobra con que cuentan los gobiernos nacionales en el manejo de las normas que rigen el sistema internacional de patentes, cuya finalidad es facilitar el comercio y la inversión en la economía mundial y abrir un margen suficiente en las diferencias nacionales relativo al desarrollo económico y la política pública (WIPOa, s/f).

Con base en el estudio de las patentes se han resaltado los efectos negativos de la migración de la fuerza de trabajo innovadora en los países de origen, incluso se determinó que este problema afecta en específico a los países periféricos proveedores de ese talento y, en menor medida, a las naciones desarrolladas. Breschi et al. (2014) encontraron, a partir del estudio de las patentes, que los países con mayores flujos migratorios de fuerza de trabajo calificada y altamente calificada aumentan la innovación, pero la pérdida de capital humano no se compensa con flujos de conocimiento inversos; la emigración favorece que los países de origen converjan hacia la frontera de la tecnología. 
Zavodny (2011) destaca que a pesar de que los inmigrantes altamente calificados logran patentes al doble de la tasa de los nativos, los formuladores de política brindan poca importancia a la reforma migratoria como una forma de impulsar la economía, toda vez que la política de inmigración afecta la innovación y el crecimiento del empleo de los nativos.

A lo largo de la historia, los inventores han resuelto un sinnúmero de situaciones, de ahí que su figura adquiera una dimensión relevante para toda la sociedad, desde las invenciones más básicas hasta los grandes avances en la ciencia, la tecnología, la comunicación y las ciencias de la salud. La crisis sanitaria de la covid-19 agudizó la crisis económica y tecnológica y mostró la trascendencia actual de científicos y tecnólogos. Con el objetivo de incentivar la creatividad a favor de la sociedad es preciso conocer cuáles son los obstáculos que limitan su creatividad y obstaculizan el patentamiento propio de sus invenciones, asimismo impulsar y facilitar los medios necesarios, económicos, materiales y de infraestructura, para que el talento explote su capacidad creativa.

El análisis de la estadística sobre patentes y sus generadores permite observar los flujos de conocimiento a partir de la nacionalidad de los inventores y determinar qué naciones receptoras, hasta cierto punto, dependen de la invención de extranjeros para mantener su competitividad internacional, con fundamento en su capacidad de atracción e implementación de la invención patentada, en particular de la atracción y dependencia de la migración altamente calificada, pues los inventores son una fracción de ese grupo selecto. Adicionalmente, permite conocer en qué áreas del conocimiento están innovando y por lo tanto cuáles áreas estratégicas del desarrollo podrían ser un foco de atención para los tomadores de decisiones. Los puntos esbozados serán abordados mediante los datos globales de propiedad intelectual y de patentes.

J. Shapiro y A. Hassett (2005) afirman que el desarrollo y la aplicación de la innovación dependen de los aspectos legales y reglamentos que protegen los derechos de la propiedad intelectual de los inventores y de quienes transfieren esos derechos. Es de suponer que cuando estos lineamientos o procedimientos de protección se vuelven un obstáculo, desincentiven la creatividad y el interés de patentar una invención en la oficina de origen e incentivar la emigración de inventores. Los mexicanos que buscan protección en México sólo han logrado patentar 27.6 por ciento de las solicitudes emitidas entre 1995-2019, éstos representan 5.9 por ciento del total de inventores que emitieron una solicitud en la oficina de México en el periodo referido. Entre 1995-2019, 74.2 por ciento de los 
inventores mexicanos buscaron protección de sus invenciones en una oficina extranjera, en el periodo reciente (2015-2019) esa cifra es de 84.5 por ciento y 53.8 por ciento ya se han aprobado.

Por ende, es de especial interés en este estudio situar a México en materia de patentes e inventores en el ámbito mundial y en el contexto latinoamericano. Se selecciona a las primeras cuatro oficinas con el mayor número de solicitudes de patentes a escala mundial (China, Estados Unidos, Japón y Corea del Sur) y a las dos principales de América Latina (Brasil y México) en ese orden de importancia. En el caso de México esta clasificación resulta adecuada, ya que su oficina figura entre las 20 principales con el mayor número de solicitudes de patentes en el nivel mundial y la segunda de países latinoamericanos.

Se examinan los flujos de patentes por oficina y origen del inventor dentro de los países seleccionados y se comparan los resultados con énfasis en México. En cuanto al análisis de tendencia de las solicitudes de patentes se cubre un horizonte temporal de 1980-2019. Posteriormente, las patentes aprobadas se analizan en dos periodos 1980-2019 y 2015-2019, así como las tasas de emigración, de inmigración y de patentes por oficina y origen nacional del inventor.

El estudio se compone de cinco secciones: la primera ofrece datos, definiciones e indicadores; la segunda trata de manera sucinta los alcances del Tratado de Libre Comercio de América del Norte y el Tratado entre México, Estados Unidos y Canadá en materia de patentes; la tercera resalta la importancia de las patentes y la innovación en la era actual de la globalización; en la cuarta se analiza a México en el contexto mundial y latinoamericano en materia de patentes por oficina y origen nacional del inventor; en la última se brindan las conclusiones.

\section{Datos, definiciones e indicadores}

El estudio se basa en datos obtenidos de la página WIPO sobre patentes, presentación directa y entradas en la fase nacional del PCT; las solicitudes y patentes otorgadas, y las definiciones fueron tomadas de la página y documentos oficiales de la institución.

La WIPO define a la propiedad intelectual (PI) como un bien, producto de la inteligencia, la creatividad y la imaginación humana. Existen dos tipos, cada una con sus leyes específicas, la industrial y la de derechos de autor. La primera se refiere a los bienes inmateriales creados principalmente por el avance de la tecnología, la 
industria y el comercio, entre los que se encuentran las patentes (instrumento legal que protege a las invenciones cuyo propósito es su aplicación en el mercado y evitar su réplica sin el pago de una retribución económica) objeto de este estudio; incluye también los diseños industriales, marcas de producto, marcas de servicio, secretos industriales y las indicaciones geográficas y denominaciones de origen, que salen del alcance de la presente investigación. La propiedad industrial y los derechos de autor se consideran un bien o activo, ya que ambos tipos de propiedad intelectual pueden generar ingresos y beneficios sociales.

\section{Definiciones y aspectos relevantes de las patentes}

1. Las patentes de invención protegen máquinas, procesos, composiciones químicas y otros tipos de invenciones valiosos por su utilidad.

2. Una invención es una elaboración mental existente en la mente del inventor y no tiene sustancia física.

3. Patente: documento legal que concede a su titular el derecho exclusivo de controlar el uso de una invención. Faculta al titular de decidir si la invención puede ser empleada por terceros y de qué forma. Como contrapartida de ese derecho, el titular de la patente pone a disposición del público la información técnica relativa a la invención.

4. El plazo de protección de una patente puede variar de país en país, pero en ningún caso debe ser inferior a 20 años a partir de la fecha de presentación de la primera solicitud de patente a escala mundial. Las patentes son «territoriales»; tienen efecto sólo en los países o regiones en los que se ha presentado la solicitud y concedido la patente.

5. Las condiciones principales que debe cumplir la invención para obtener la protección por patente, además de las administrativas, son diversas: a) Ser novedosa, es decir, presentar un elemento o característica que no forme parte del conocimiento existente en su ámbito técnico. b) No puede ser deducida por una persona de nivel medio del mismo ámbito técnico, esto es evidente.c) Susceptible de aplicación industrial, lo que significa que debe poder utilizarse con fines industriales o comerciales sin limitarse a ser un fenómeno meramente teórico. d) La materia objeto de la invención debe considerarse «patentable» conforme a la legislación. e) La invención debe divulgarse por medio de una solicitud de forma clara y completa, que posibilite su reproducción por una persona de nivel medio del mismo ámbito técnico. 
1. En las estadísticas de PI se considera que el solicitante mencionado en primer lugar es el titular de la solicitud.

2. Las cifras por oficina indican el lugar en que solicitan protección los titulares de derechos y las cifras por origen quiénes solicitan protección. En las estadísticas por oficina y por origen se señala el movimiento real de derechos de PI entre países.

3. El término «residente» se usa para las solicitudes presentadas por solicitantes en su oficina nacional. Las cifras de residentes por origen corresponden a la suma de solicitudes mostradas en una oficina nacional o en una oficina regional. A efectos estadísticos las solicitudes proporcionadas por un residente son las emitidas ante la oficina de PI del Estado o la jurisdicción en que reside el solicitante, nombrado en primer lugar en la solicitud, o la oficina que actúe en nombre de dicho Estado o jurisdicción.

4. Los términos «no residente» $y$ «en el extranjero» tienen que ver con las solicitudes presentadas en oficinas de otros países. «No residente» se usa para las estadísticas por oficina cuando el solicitante nombrado en primer lugar vive en otro país; «en el extranjero» se emplea para las estadísticas por origen, es decir, cuando una oficina recibe una solicitud de parte de un extranjero, se trata de una solicitud presentada por un no residente. En cambio, cuando un solicitante muestra una solicitud en una oficina de otro país, se trata de una solicitud presentada en el extranjero que toma en cuenta el origen del solicitante.

5. Una solicitud de patente es un documento en el que se deja constancia del entendimiento entre el inventor y la oficina de patentes, del que resulta la concesión de una patente.

6. Una patente es válida una vez que ha sido concedida y no ha prosperado oposición alguna en su contra ante la autoridad competente.

7. Patente en vigor: derechos de propiedad intelectual vigentes, a fin de asegurar su vigencia debe mantener la protección.

8. Una invención patentada puede ser licenciada, o sea, el titular de la patente concede permiso a otra persona/organización para hacer, usar, vender, etcétera, su invención patentada. A diferencia de vender o transferir una patente a otra parte, el licenciante conserva los derechos de propiedad sobre la invención patentada.

De acuerdo con WIPO (tratados y partes contratantes), para obtener protección de una patente en varios países se debe presentar una solicitud nacional de 
patente en cada oficina del país de interés (vía directa). Otra forma es mediante el Convenio de París, previa solicitud en un país con convenio. Este convenio facilita mostrar varias solicitudes de patente por separado en otros países miembros, dentro de un plazo de 12 meses a contar desde la fecha de presentación de la primera solicitud de patente, con la ventaja de reivindicar en esos países la fecha de la primera solicitud. La adhesión de México al Convenio de París fue el 20 de julio de 1903 y entró en vigor el 7 de septiembre de ese mismo año.

Una opción menos costosa en tiempo y dinero es a través de una solicitud internacional en virtud del Tratado de Cooperación en Materia de Patentes (PCT); cualquier residente o ciudadano de un país miembro del PCT puede presentar una solicitud internacional única con validez en distintos Estados contratantes o en todos ellos, una única solicitud en un solo idioma, además se paga la tasa en una divisa única. El PCT está conformado por 153 países contratantes, 22 pertenecen a América; de éstos 12 se incorporaron a partir del año 2000. Estados Unidos (1978), Japón (1978), Brasil (1985) y Corea del Sur (1984) son los más antiguos, China se adhirió en 1994 y México en octubre de 1994, el tratado entró en vigor el 1 de enero de 1995. De igual forma, México firmó el Convenio de la OMPI en julio de 1967 y lo ratificó el 14 de marzo de 1975, el 14 de junio de 1975 entró en vigor (WIPO, Notification no. 39).

En México, la solicitud de una patente aplica solamente en territorio nacional, en ese sentido, para proteger una invención a escala internacional es preciso mostrar dicha solicitud en cada país de interés, o bien seguir las rutas descritas a fin de buscar protección en diversos países por medio de una única solicitud internacional (PCT) o varias (Convenio de París). Todo mexicano tiene derecho a presentar una solicitud internacional de patente si es nacional o residente de uno de los Estados contratantes del PCT, la solicitud internacional deberá mostrarse en la oficina autorizada, en este caso ante el Instituto Mexicano de la Propiedad Industrial (IMPI).

Para contar con una solicitud internacional de patente en PCT, los solicitantes o al menos uno de los interesados deben residir en el país contratante del PCT. Este trámite tiene en promedio una duración de 18 meses, desde la fecha de presentación de la primera solicitud de patente (fecha de prioridad) hasta un máximo de 30 meses. No es necesario esperar a que venza el plazo de 30 meses para entrar en la fase nacional, ya que se puede solicitar la entrada anticipada. Previo al ingreso se debe asignar los Estados en los que se quiere patentar la invención y cumplir los requisitos nacionales, como el pago de las tasas nacionales, la presentación de 
la solicitud traducida y la designación de mandatarios locales si procede, trámites que deben realizarse antes de que finalice el trigésimo mes a contar desde la fecha de prioridad. Tras la entrada a la fase nacional o regional de patentes comienza el proceso para determinar si se concede o no la patente (figura 1).

Patentar una invención mediante PCT o el Convenio de París lleva menos tiempo que patentar en la oficina de México ante el IMPI: el tiempo promedio desde que ingresa la solicitud hasta que es emitido un dictamen de conclusión, sea una concesión o una negativa, es de tres a cinco años. El costo por la presentación de una solicitud de patente y sus anexos hasta por 30 hojas es de 4 mil 550 pesos, cada hoja adicional cuesta 61 pesos (Diario Oficial de la Federación, DOF, 2604/2018). En el caso de un diseño industrial el tiempo estimado es de un año y para un modelo de utilidad de dos. La tarifa por los servicios que presta el instituto establece que los inventores independientes, la micro y pequeña industria, las instituciones de educación pública y los institutos de investigación y desarrollo tecnológico del sector público pagarán únicamente 50 por ciento de las cuotas de los derechos que correspondan, previa petición por escrito conforme a la Cuarta Disposición de la Tarifa (IMPI, 2011).

\section{FIGURA 1}

Vías para patentar invenciones en varios países. Vía el Convenio de París y PCT

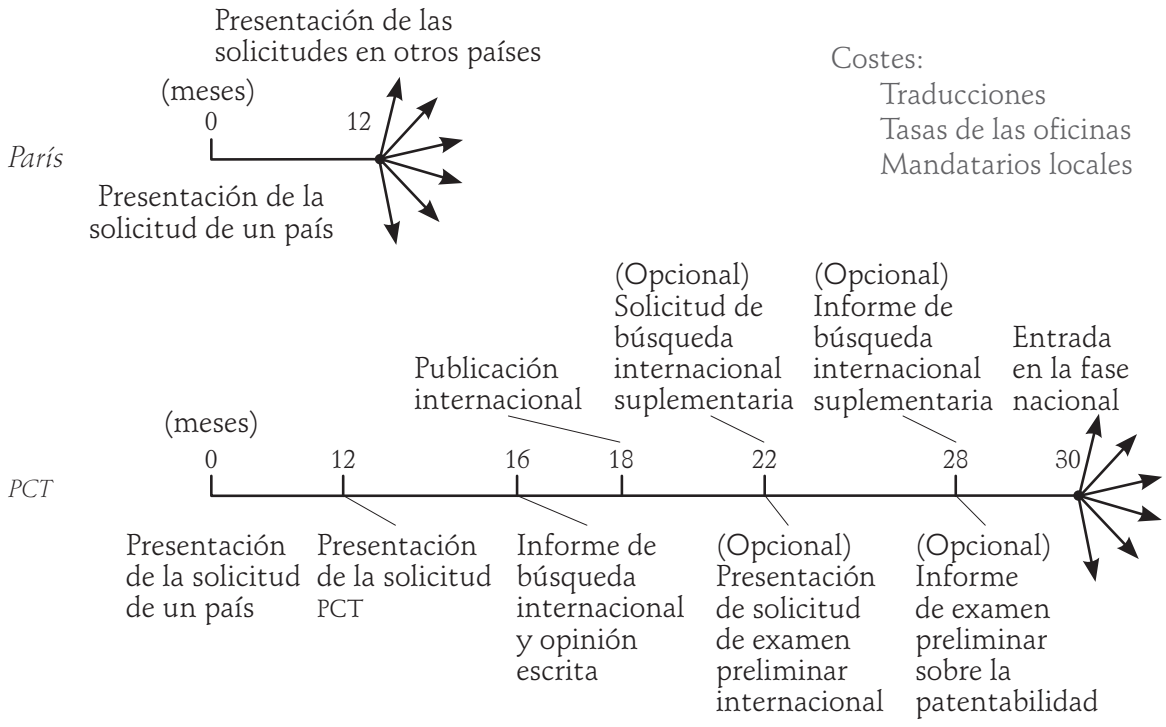

Fuente: WIPO, 2017 


\section{Indicadores}

Los indicadores que se presentan en la sección «Líderes mundiales y latinoamericanos en patentes otorgadas (inventores)» se estiman para las patentes otorgadas, pues son las que efectivamente se pueden comercializar, además de que esta categoría ya ha pasado las pruebas que permiten considerarla una invención, por lo tanto, es innovadora y útil a la sociedad, con la intención de que esto último se cumpla cabalmente se debe producir y comercializar la patente. La tasa de emigración es una aproximación subestimada de la movilidad de inventores, se calcula con base en la metodología de Miguélez y Fink (2013) y la tasa de inmigración se estima de manera similar.

$$
\begin{aligned}
\text { Tasa de emigración } & =\frac{\text { diáspora }}{(\text { residentes }+ \text { diáspora })} * 100 \\
\text { Tasa de inmigración } & =\frac{\text { No residentes }}{(\text { residentes }+ \text { no residentes })} * 100
\end{aligned}
$$

Donde: diáspora $=$ inventores nacionales del país que residen en el extranjero residentes $=$ inventores nacionales residentes en el país no residentes $=$ inventores extranjeros que buscan patentar

o patentan en una oficina extranjera

\section{El TLCAN y T-MEC en materia de patentes}

En 1994, México firma el TLCAN con Estados Unidos y Canadá y el 1 de octubre de ese año el Tratado de Cooperación en Materia de Patentes y con la OMPI el 1 de enero de 1995. El TLCAN contempla en el capítulo XVII, artículos 1701-1718 (SICE-Sistema de Información sobre Comercio Exterior) ${ }^{1}$ un acuerdo con relación a la propiedad intelectual entre las partes involucradas para otorgar protección y defensa adecuada y eficaz. Los inventores de ambos países se encuentran entre los principales solicitantes de patentes de la oficina de México, con

${ }^{1}$ Con objeto de otorgar protección y defensa adecuada y eficaz a los derechos de propiedad intelectual cada una de las Partes aplicará, cuando menos, este capítulo y las disposiciones sustantivas de: a) el Convenio de Ginebra para la Protección de los Productores de Fonogramas Contra la Reproducción no Autorizada de sus Fonogramas, 1971 (Convenio de Ginebra); b) el Convenio de Berna para la Protección de Obras Literarias y Artísticas, 1971 (Convenio de Berna); c) el Convenio de París para la Protección de la Propiedad Industrial, 1967 (Convenio de París); d) el Convenio Internacional para la Protección de las Obtenciones Vegetales, 1978 (Convenio UPOV), o la Convención Internacional para la Protección de Nuevas Variedades de Plantas, 1991 (Convenio UPOV). 
la primera posición Estados Unidos y la décima Canadá. El TLCAN y el PCT marcan una etapa importante en materia de patentes para México, facilitan la emisión de solicitudes de patentes desde países extranjeros y viceversa; lo que a su vez favorece una modalidad de intercambio desigual a través del sistema de protección de patentes. A la vez que la oficina de México se coloca entre las 15 más atractivas en el nivel mundial y la segunda entre los países latinoamericanos, paradójicamente ha generado un proceso de transferencia de conocimientos y riqueza donde los países ricos siguen siendo los más beneficiados.

Conforme al estudio de Méndez Cruz (2014), se estima la transferencia de bienestar de Deardorff cuyo resultado indica si el tipo de transferencia es positivo o negativo. El cálculo considera el caso de México y Estados Unidos dentro del periodo 1995-2019, bajo la premisa de que los nacionales de Estados Unidos emitieron 50.6 por ciento del total de solicitudes en la oficina de México y 53.9 por ciento fueron emitidas por extranjeros, 49.4 por ciento de las solicitudes de patentes de mexicanos en el extranjero se emiten en la oficina de ese país.

De acuerdo con la metodología de Deardorff, dado que la diferencia es negativa se corrobora que se trasfiere más riqueza desde México a Estados Unidos que de este país hacia México. Lo mismo sucede con relación a los resultados para el resto de los países en los que patentan los mexicanos en el extranjero, entre los que se encuentran las oficinas de Europa, Brasil, Canadá y China. Los hallazgos confirman también que las disposiciones del TLCAN en materia de patentes y PCT, como apunta Deardorff, poco han contribuido en incentivar la innovación tecnológica nacional a fin de que se traduzca en patentes de y para mexicanos. En cambio, se ha fortalecido el intercambio desigual —en todas sus dimensiones: materiales y humanas - entre México y Estados Unidos, la emigración de inventores mexicanos hacia ese país y la dependencia de patentes de estadounidenses para mantener su posición en el ranking de las oficinas más atractivas para inventores extranjeros (cuadro 1).

Según Carlos Correa (2018), la política nacional debe promover la innovación y el acceso a sus resultados, pues la protección de la PI por sí sola no conduce a más o mejor innovación. En realidad un sistema más complejo y coercitivo de PI inhibe las innovaciones al erigir a la tecnología y a los recursos financieros como barreras de acceso a potenciales participantes. La difusión del conocimiento y la apertura a las tecnologías son fundamentales, argumenta que desde el punto de vista teórico y práctico es inadmisible aceptar «que la propiedad intelectual tiene el mismo efecto independientemente del nivel de desarrollo» (Correa, 2018:1) no 
es lo mismo tener una industria diversificada y avanzada que depender de las tecnologías, la producción y el comercio de productos básicos.

\section{CUADRO 1}

Transferencia de bienestar de México a Estados Unidos medida por solicitudes de patentes y patentes otorgadas, 1995-2019

\begin{tabular}{lccccc}
$\begin{array}{c}\text { Cálculo para } \\
\text { Estados } \\
\text { Unidos }\end{array}$ & $\begin{array}{c}\text { Nacionales } \\
\text { de México } \\
(A)\end{array}$ & $\begin{array}{c}\text { Mexicanos } \\
\text { en Estados } \\
\text { Unidos }(B)\end{array}$ & $\begin{array}{c}\text { Total }(A+B) \\
\text { (A) }\end{array}$ & $\begin{array}{c}\text { Nacionales de } \\
\text { Estados Unidos } \\
\text { en México }(D)\end{array}$ & $\begin{array}{c}\text { Diferencia } \\
(C)-(D)\end{array}$ \\
\hline $\begin{array}{l}\text { Solicitudes } \\
\text { Patentes }\end{array}$ & 20598 & 7336 & 27934 & 173015 & -145081 \\
\% patentes & 27683 & 3018 & 8701 & 99602 & -90901 \\
\hline $\begin{array}{l}\text { Cálculo para } \\
\text { otros países }\end{array}$ & $\begin{array}{c}\text { Nacionales } \\
(\text { A) }\end{array}$ & $\begin{array}{c}\text { Nacionales } \\
\text { en otros países } \\
(B)\end{array}$ & $\begin{array}{c}\text { Total }(A+B) \\
=(C)\end{array}$ & $\begin{array}{c}\text { Extranjeros } \\
\text { en México (D) }\end{array}$ & $\begin{array}{c}\text { Diferencia } \\
(C)-(D)\end{array}$ \\
\hline $\begin{array}{l}\text { Solicitudes } \\
\text { Patentes }\end{array}$ & 20598 & 7512 & 36534 & 147989 & -111455 \\
$\%$ patentes & 5683 & 6865 & 12836 & 87472 & -74636 \\
\hline
\end{tabular}

\section{4}

Nota: excluye no especificado.

Fuente: estimación propia con base en datos de WIPO, 1995-2019.

Metodología Deardorff tomada del estudio de Méndez, 2014.

Después de una serie de negociaciones que iniciaron el 18 de mayo de 2017, el 1 de julio de 2020 entró en vigor el T-MEC, acuerdo comercial que sustituyó al TLCAN, cuyo capítulo 20 (artículo 20.15) contempla las disposiciones generales sobre los derechos de propiedad intelectual (GOB, s/f), y los compromisos de cooperación para mejorar la calidad y eficiencia de los sistemas de registro, simplificar procedimientos y procesos, así como facilitar el intercambio y la búsqueda y examen de las partes. El 28 de enero de 2020 se estableció el acuerdo (IMPI, 2020) entre la Oficina de Patentes y Marcas de los Estados Unidos de América (USPTO, por sus siglas en inglés) y el IMPI, cuya finalidad consiste en hacer más eficiente la revisión de las patentes, acuerdo que se alinea con los compromisos T-MEC en materia de patentes. Al respecto Raúl Delgado (2020) indica que ambos tratados en materia de patentes operan como un dique vigoroso frente a cualquier tentativa de trascender el neoliberalismo y favorece la emigración de científicos y tecnólogos mexicanos formados en áreas estratégicas para la innovación. 


\section{Importancia de las patentes y la innovación}

En palabras de J. Shapiro y A. Hassett (2005), el papel de la innovación en la vida económica global es más importante que nunca. Corea del Sur con recursos naturales relativamente escasos aumentó el valor de su producción e ingreso per cápita tres veces más rápido que Brasil, país rico en recursos naturales; lo atribuyen a la apertura de Corea a la innovación tecnológica propia e importada, ya sea a través de la inversión extranjera directa o mediante acuerdos de licencias, mayor inversión en educación pública, apertura y adaptación a las nuevas tecnologías y formas de hacer negocio. Indican que los beneficios de la innovación son para quienes los explotan y que el desarrollo y la aplicación de la innovación dependen de los aspectos legales y reglamentos que protegen los derechos de la PI de los inventores y de quienes transfieren esos derechos.

Adicionalmente, puntualizan que el ritmo en que las naciones subdesarrolladas crecen y se modernizan depende de modo sustancial de las transferencias de innovación que los inventores hacen a las naciones avanzadas, por lo que la protección de la PI en los países subdesarrollados es fundamental en la determinación del alcance de esas transferencias. Ello supondría que la transferencia de conocimientos de tecnólogos y científicos de la periferia tiene una incidencia significativa en sus países de origen, lo que contrasta con el hecho de que las patentes de los extranjeros que trabajan en los países centrales no son dueños de las patentes, y a final de cuentas deben comprar o licenciar patentes que han creado los nacionales de los países periféricos, esto es, hay una doble transferencia de valor: por un lado, al exportar mano de obra altamente calificada a un costo menor al de los nativos; por otro, al tener que adquirir los derechos de explotación y comercialización de los nacionales por la vía de la compra o licenciamiento de las patentes.

Si bien M. Kalanje (s/f) destaca que la innovación se relaciona con la comercialización de nuevas ideas, una invención no necesariamente se identifica con dicho aspecto puesto que no todas se comercializan, de ahí que sólo algunas propician innovaciones. La anterior situación resulta contradictoria con el espíritu de las patentes, ya que se supone que únicamente se puede patentar una idea que está dirigida a ser llevada al mercado, lo que implica que la idea efectivamente se convierte en una innovación: una invención que permanece como idea no se constituye en innovación y, en consecuencia, no debería ser patentable.

Las invenciones requieren de protección, gestión y financiamiento para su producción; su comercialización es una manera de aprovechar el conocimiento, 
por lo que se considera una inversión de gran potencial (WIPOb, s/f). La empresa Intellectual Property Bewertungs (IPB) ofrece tres métodos para valorar las patentes, basados en tres elementos: Costos. El valor de la patente es igual a los costos en investigación y desarrollo (I+D) asociados con la patente. Ingresos. El valor de la patente es igual al flujo de ingresos que el titular de la patente tiene previsto obtener durante la vida de la patente. Mercado. Negociación entre lo que se quiere pagar y recibir entre el comprador y el vendedor por un activo, en este caso de la patente (WIPOb, s/f).

Para las economías centrales la innovación es clave en el crecimiento del producto y se ha observado una relación positiva entre la inversión en educación y el gasto en I+D con el incremento en la producción. Referente a los países exitosos con estrategias nacionales de innovación se identifican como economías de altos ingresos a Suiza, Suecia, Estados Unidos, Países Bajos y Reino Unido y como economías de ingresos medios altos a China, Malasia, Bulgaria, Tailandia y Montenegro (WIPO, 2019). La globalización tecnológica y los mercados globales exigen una mayor inversión en investigación y desarrollo, educación y capacitación, información y cooperación para hacer frente a los acelerados cambios tecnológicos y aprovechar las oportunidades presentes, premisa que en la práctica está limitada por la propia existencia de los sistemas de protección comercial y de la propiedad intelectual que agudizan la exclusión y las disparidades entre centro y periferia. La utilización de nuevas tecnologías como elemento clave de la innovación, la investigación y el desarrollo, y los recursos humanos en formación permanente desempeñan un papel de primer orden en la oferta de las competencias y adaptación constante a los cambios tecnológicos y en la incursión hacia una sociedad basada en el conocimiento (Comisión Europea, 1995).

El gasto en investigación y desarrollo y las solicitudes de patentes se encuentran altamente correlacionados (WIPO, 2019). La estadística que se exhibe muestra que los países con alto nivel de inversión en I+D, tienden a un alto índice de participación de residentes como es el caso de Corea del Sur y China, mientras que los que tienen bajos índices de I+D como México y Brasil tienden a depender de la invención de extranjeros. Un caso particular es Estados Unidos que se caracteriza por ser un importador neto de tecnología y de capital humano altamente calificado y es el país con el mayor gasto en términos absolutos en Investigación y Desarrollo, seguido de China, Japón, Alemania y República de Corea (gráfica 1).

En gasto I+D como porcentaje del PIB sobresale Israel (4.58 por ciento), República de Corea (4.55 por ciento), Suecia (3.31 por ciento), Japón (3.20 por ciento), 
seguidos de Austria, Dinamarca, Alemania y Estados Unidos con 2.8 por ciento respectivamente. México es uno de los países que menos invierte en I+D, en 2017 ocupó la posición 64 en gasto bruto en I+D como porcentaje del PIB (0.49 por ciento) y en la actualidad el gasto ha disminuido durante tres años consecutivos, además, se ubica entre los países con la menor inversión en educación terciaria, apenas invierte 1.3 por ciento del PIB. De los países que más invierten en educación superior sobresalen Estados Unidos, Costa Rica, Chile y Corea del Sur (gráfica 1).

Las fuentes de financiamiento también impactan en los sistemas de innovación, en México las empresas privadas apenas participaron en 2017 con 19.05 por ciento en el Gasto en Investigación Científica y Desarrollo Experimental (GIDE), su participación descendió en 13.81 puntos porcentuales respecto de 2010, mientras que en el resto de los países en estudio el financiamiento privado supera 55 por ciento, China (76.48 por ciento), Corea del Sur (76.23 por ciento), Japón (78.27 por ciento), Estados Unidos (22.78 por ciento) y Brasil (55.48 por ciento). México requiere una mayor participación de las empresas privadas en el financiamiento de las actividades de investigación e innovación y su compromiso social en la generación de conocimiento, de tecnologías, en la productividad y competitividad económica del país (Amador, 2017).

Estos resultados explican hasta cierto punto por qué los países centrales siguen encabezando la lista del Índice Mundial de Innovación 2020 publicado cada año por la WIPO, y economías de ingresos medios como China, Corea del Sur y Brasil siguen ganando posición en el ranking, mientras que México, país de ingreso medio-alto, pierde posición al invertir menos en I+D y educación, resultado que se ve reflejado en su desempeño.

En 2010 Ángel Gurría, entonces Secretario General de la Organización para la Cooperación y el Desarrollo Económicos (OCDE) manifestaba que México debía crear un marco propicio para la innovación y que ésta debería de ser la piedra angular de la política nacional de desarrollo para lograr un crecimiento económico sostenido y de largo plazo que le permitiera hacer frente a los desafíos globales. Luego de 11 años es propicio retomar estas recomendaciones de parte de México, pues sigue perdiendo competitividad frente a otras economías, lo que fortalece su dependencia de la innovación de extranjeros y motiva a su capital humano altamente calificado a formar parte de su creciente diáspora. A diferencia de lo que afirmaba el secretario general de la OCDE, no se trata de un acto de voluntarismo sino de reconocer las condiciones de inserción subordinada de la economía mexicana, que ha sido el acicate relativo a la insuficiencia de 
crecimiento, la deficiente habilidad de generar capacidades científicas y tecnológicas y el incentivo para el aumento de la migración altamente calificada.

\section{GRÁFICA 1}

Posición y Gasto Bruto en Investigación y Desarrollo (GBID) como porcentaje del PIB 1996-2018. Países con el mayor número de solicitudes de patentes a nivel mundial y los dos principales de América Latina, 2018

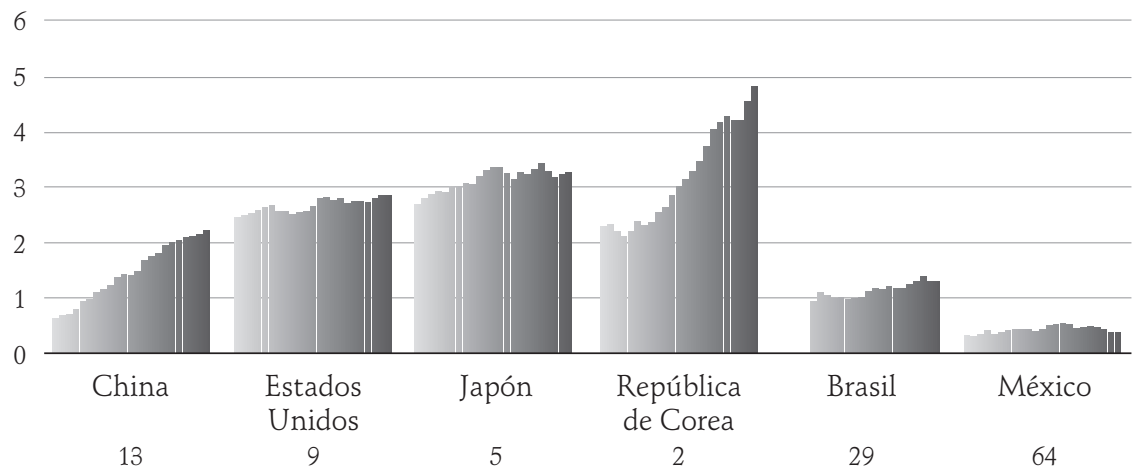

\section{8}

Fuente: elaboración propia con datos de UNESCO, 2020.

Gold, Morin y Shadeed (2017) encontraron que la PI conduce a mayores niveles de transferencia de tecnología y a una mayor inventiva nacional. La literatura consultada en su estudio sugiere que para los países en desarrollo se observa un efecto directo de la PI en el crecimiento económico cuando opera una serie de factores: la capacidad de investigación y desarrollo del país, la riqueza per cápita, la naturaleza y eficacia de sus instituciones, su etapa de desarrollo y la volatilidad económica. Los autores citados recurren a Maskus para indicar que los países en desarrollo se benefician más de niveles altos de PI cuando invierten en capital humano, en economías más abiertas y en políticas con fuertes antimonopolios.

La Comisión sobre Derechos de Propiedad Intelectual (2002), integrada por Barton, Alexander, Correa, Mashelkar, Samuels y Thomas, expone que el desarrollo de la propia capacidad tecnológica constituye un factor definitivo para el crecimiento económico y la reducción de la pobreza, capacidad que determina hasta qué punto se pueden asimilar y aplicar las tecnologías extranjeras obtenidas mediante patentes o transferencias de patentes. Puntualiza que las prácticas de los países desarrollados pueden llevar a la obtención de patentes de países en desarrollo sin un acuerdo acerca de la distribución de los beneficios de su comercialización, 
por lo que la protección de patentes es fundamental, aunque en algunos casos puede imponer restricciones sobre las exportaciones de los países en desarrollo a los países desarrollados y estándares mínimos de protección de la PI. Además explica que los beneficios de la PI varían entre países y «podrían ocasionar más gastos que beneficios cuando se aplican a países en desarrollo que dependen, en gran parte, de conocimientos (o productos que incorporan conocimientos) concebidos de otras partes del mundo para satisfacer sus necesidades básicas y promover su desarrollo» (CDPI, 2002:4). Hace hincapié en la importancia de patentar, pues permite a los inventores y fabricantes recuperar sus inversiones en I+D y obtener beneficios a cambio de la divulgación de los conocimientos en los que se basa la invención o mediante la comercialización de ese conocimiento con la autorización del titular de la patente.

Respecto a las teorías económicas de costos y beneficios de las patentes, Mazzoleni y Nelson (1996) destacan cuatro: 1. Teoría de inducción-invención: la anticipación de recibir patentes proporciona motivación para una invención útil, es decir estimula la creatividad. 2. Teoría de la divulgación: las patentes facilitan un amplio conocimiento y uso de las invenciones al inducir a los inventores a divulgar sus invenciones. 3. Teoría del desarrollo y la comercialización: las patentes inducen la inversión necesaria para desarrollar y comercializar invenciones. 4. Teoría del desarrollo de prospectos: bajo esta teoría refieren que las patentes permiten la exploración ordenada de amplios prospectos para invenciones derivadas. Argumentan que para muchas industrias la perspectiva de una patente no parece ser un incentivo que aumente la inventiva útil porque se asume que el beneficio social de una invención particular es estrictamente su valor de uso final.

De acuerdo con la United States Patent and Trademark Office (USPTO) (2019) las empresas que obtienen licencias de patentes generalmente controlan los procesos de fabricación, distribución y comercialización; esto ocurre cuando el inventor decide no fabricar su propia invención. Asimismo, los inventores que son titulares de patentes tienen mayores ingresos, relación que persiste después de eliminar la influencia de la ocupación, el estado migratorio, entre otras características. Se reitera también la persistente desigualdad por género: las mujeres inventoras ganan menos que sus pares varones. Las patentes se asocian con mejoras en los indicadores de desempeño en el nivel de empresas, generan empleo y favorecen las ventas y ofertas de productos. A escala empresarial las patentes aumentan la eficiencia transnacional, proporcionan incentivos para una inversión eficiente y promueven el financiamiento y la innovación; al tiempo que dan seguridad a las 
empresas para revelar sus inversiones a posibles licenciatarios sin el riesgo de que ocurra una apropiación indebida, y evitan el monopolio. Evidentemente, la capacidad legal de hacer valer los derechos de las patentes está resguardada por organismos internacionales, lo que implica que existen un marco y una estructura supranacionales que protegen a los propietarios de las patentes.

Al respecto, la Comisión Europea (1995:6) advierte que la calidad del sistema educativo, el marco reglamentario normativo y fiscal, el entorno competitivo, los socios de las empresas, la legislación sobre patentes y de la propiedad intelectual, la infraestructura pública de investigación y los servicios de apoyo a la innovación son factores inhibidores o favorables. La activación y fortalecimiento de esos factores puede fortalecer los sistemas de innovación en los países en desarrollo. En seguida se presentan algunas reflexiones de la Comisión impresas en el Libro Verde de la Innovación en el que destacan elementos que explican el éxito de Estados Unidos y Japón e identifican prioridades y acciones en busca de mejorar y hacer un entorno más favorable para la innovación; cabe resaltar que se resumen aquí por su utilidad para los países en desarrollo que están incursionando o fortaleciendo sus sistemas de protección de PI (cuadros 2 y 3).

\section{CUADRO 2}

Factores de éxito para impulsar la innovación

Estados Unidos

Fortalecimiento de la investigación.

Una proporción mayor de ingenieros y científicos en la población activa.

Esfuerzos de investigación mejor coordinados (particularmente en los sectores aeronáutico, electrónico y espacial).

Una estrecha relación universidad-industria que permite la aparición de numerosas empresas de alta tecnología.

Capital riesgo más desarrollado e inversión en alta tecnología. Un mercado bursátil para pymes dinámicas, el Nasdaq.

Tradición cultural favorable al riesgo, espíritu empresarial y fuerte aceptación social de la innovación.
Japón

Fortalecimiento de la investigación

Una proporción mayor de ingenieros y científicos en la población activa.

Gran capacidad de adaptar la información tecnológica y una gran tradición de cooperación entre empresas en materia de $\mathrm{I}+\mathrm{D}$.

Una cooperación universidad/empresa en fuerte progresión.

Relaciones fuertes y estables entre las finanzas y la industria, que favorecen los beneficios y las estrategias a largo plazo.

Una cultura favorable a la aplicación de las técnicas y a la mejora permanente. 
Menos coste de registro de las patentes, sistema de protección jurídica unificado y favorable a la explotación comercial de las innovaciones.

Plazos de creación de empresas y formalidades administrativas reducidas.
Práctica normal de estrategias concertadas entre empresas, universidades y poderes públicos.

Fuerte movilidad del personal en las empresas.

Fuente: elaboración propia con base en Comisión Europea, 1995:12.

\section{CUADRO 3}

Obstáculos y acciones favorables para la innovación

Obstáculos (Comisión Europea, 1995:41-62)

1. Sistemas de educación y formación inadaptados y movilidad baja.

2. Sistema financiero que parece huir de la innovación, incertidumbre y límites de financiación pública y un entorno fiscal poco favorable a la innovación.

3. Infrautilización de normas y reglamentos jurídicos, trámites burocráticos engorrosos, fórmulas jurídicas mal adaptadas.

\section{Acciones favorables (Comisión Europea, 1995:63-82):}

1. Incrementar la alerta y la prospectiva tecnológicas.

2. Una mejor orientación de la investigación hacia la innovación.

3. Desarrollar la formación inicial y permanente.

4. Favorecer la movilidad de estudiantes e investigadores.

5. Ayudar a la concienciación acerca de los efectos beneficiosos de la innovación.

6. Mejorar la financiación de la innovación.

7. Instaurar una fiscalidad favorable a la innovación.

8. Fomentar la propiedad intelectual e industrial.

9. Simplificar las formalidades administrativas.

10. Fomentar un entorno jurídico y reglamentario favorable a la innovación.

11. Desarrollar las acciones de «inteligencia económica».

12. Fomentar la innovación en las empresas, particularmente en las pymes, y reforzar la dimensión regional de la innovación.

13. Renovar la intervención pública en favor de la innovación. 


\section{México en el contexto internacional y latinoamericano en materia de patentes}

En este apartado se analizan las solicitudes de patentes y las patentes aprobadas en los periodos 1980-2019 y 2015-2019 por oficina y origen. Los datos de solicitudes de patentes por oficina (país en que solicitan protección los titulares de derechos) distingue el origen nacional de quienes solicitan protección y los clasifican en residentes y no residentes. La nacionalidad y residencia del inventor permite establecer la geografía parcial de la migración altamente calificada, pues los inventores son una categoría específica de ese grupo.

Solicitudes de patentes. Oficinas líderes a escala mundial $y$ de países latinoamericanos

Entre 1980-2019 las oficinas de Japón, Estados Unidos, China, Corea del Sur y Alemania encabezaron las oficinas que recibieron el mayor número de solicitudes del periodo, en esta clasificación las oficinas de Brasil y México son las únicas de países latinoamericanos que se encuentran entre las 15 principales, con las posiciones 13 y 14 respectivamente. Entre 2015 y 2019 China encabezó la lista y fue la oficina líder con casi 6.8 millones de solicitudes de patentes; recibió más del doble de solicitudes que la de Estados Unidos, que ahora ocupa la segunda posición con 3 millones de solicitudes. Por su parte, Japón acumuló 1.6 millones de solicitudes en el periodo, perdió su posición a favor de Estados Unidos y disminuyó de manera significativa la recepción de solicitudes (4.3 veces menos que China y dos veces menos que la de Estados Unidos). Corea del Sur mantuvo la cuarta posición con poco más de 1 millón de solicitudes. Brasil y México se colocaron en el periodo reciente en las posiciones 10 y 11 con 134 mil y 85 mil solicitudes de patentes; Brasil recibió 1.6 veces más solicitudes que México y sus nacionales emitieron 4.4 veces más solicitudes que los nacionales de México. Siguen en orden de importancia las oficinas de Argentina y Colombia con casi 19 mil y 11 mil solicitudes respectivamente.

Del total de solicitudes realizadas entre 1980 y 2019, China recibió 56.2 por ciento entre 2015-2019, Estados Unidos 23.6 por ciento, Japón 11.3 por ciento, Corea del Sur 25.7 por ciento, Brasil 20.9 por ciento y México 19.7 por ciento. Japón y Brasil recibieron el menor porcentaje de solicitudes del periodo reciente. Las oficinas de México, Brasil y Estados Unidos dependen de las solicitudes de patentes 
de extranjeros con el propósito de mantener su posición, entre 2015-2019 tan sólo 8.1 por ciento, 19.2 por ciento y 47.9 por ciento de las solicitudes emitidas corresponden a nacionales; estos países tienen altas tasas de inmigración de inventores. Por el contrario, las oficinas de China, Japón y Corea del Sur tuvieron una participación alta de sus nacionales en la emisión de solicitudes de patente: 89.9 por ciento, 81.1 por ciento y 78.0 por ciento, respectivamente (cuadro 4).

\section{CUADRO 4}

Oficinas. Porcentaje de solicitudes de residentes $1995-2019$ y $2015-2019$

\begin{tabular}{c|cccccc}
\multicolumn{1}{c}{ Periodo } & China & Estados Unidos & Japón & Corea del Sur & Brasil & México \\
\hline $1995-2019$ & $82.9 \%$ & $50.8 \%$ & $85.4 \%$ & $76.1 \%$ & $18.9 \%$ & $5.9 \%$ \\
$2015-2019$ & $89.5 \%$ & $47.9 \%$ & $81.1 \%$ & $78.0 \%$ & $19.2 \%$ & $8.1 \%$ \\
\hline
\end{tabular}

Fuente: estimación propia con datos de WIPO, 1995-2019.

La observación de los datos muestra que China igualó a Japón en 2009 y dos años después a Estados Unidos; así, Japón ocupó la primera posición de 1980 a 2005 y en 2006 fue superado por Estados Unidos, que ocupó la segunda posición en el mismo periodo. La crisis económica mundial de 2007-2009 propició que varias oficinas tuvieran tasas decrecientes en el número de solicitudes de patentes, entre ellas las de Estados Unidos y Japón que mantuvieron su liderazgo por un corto tiempo, pues entre 2009 y 2011 fueron superadas por China que exhibió una tendencia exponencial. Durante el periodo 2011-2019 Estados Unidos mantuvo un crecimiento bajo — en promedio 575 mil solicitudes por año—, suficiente para mantener la segunda posición por ese lapso, con una brecha significativa entre Japón y Corea del Sur (gráfica 2).

En tanto, Brasil y México son líderes de los países latinoamericanos desde 1980, sin embargo ambas oficinas muestran un descenso en las solicitudes de patentes: Brasil a partir de 2015 y México en 2016. Entre 2017 y 2019 las solicitudes para México decrecieron en -7.2 por ciento y las de Brasil -1.0 por ciento, en ambos casos el mayor descenso ocurrió entre los no residentes (-7.7 por ciento y -1.2 por ciento, respectivamente); este dato es relevante porque las posiciones de esas oficinas dependen de las solicitudes de no residentes (gráfica 3). 


\section{GRÁFICA 2}

Oficinas líderes mundiales en solicitudes de patentes en los periodos 2015-2019, 1980-2019 (incluye residentes y no residentes)

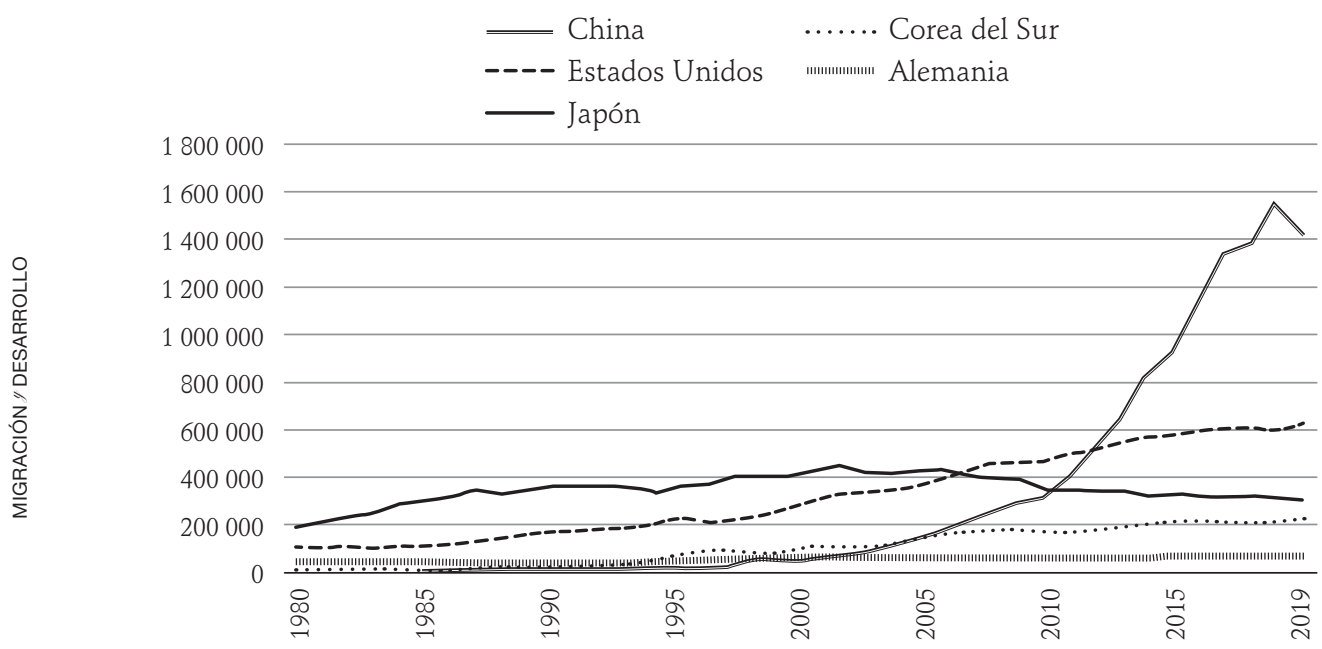

Fuente: elaboración propia con datos de WIPO, 1980-2018.

164

\section{GRÁFICA 3}

Oficinas líderes latinoamericanas en solicitudes de patentes en los periodos 2015-2019, 1980-2019 (incluye residentes y no residentes)

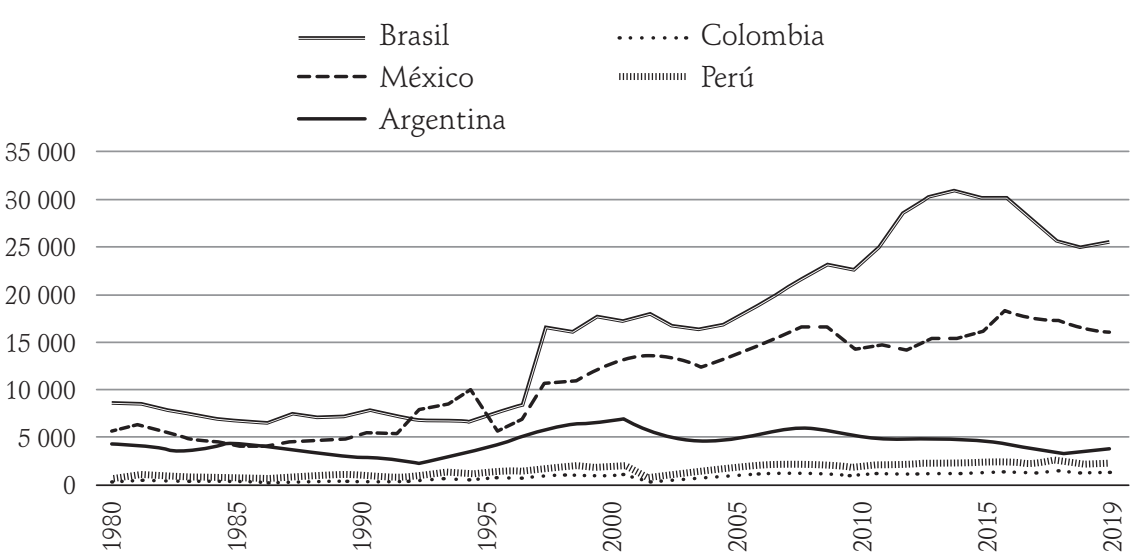

Fuente: elaboración propia con datos de WIPO, 1980-2018. 
La WIPO (2019) expone que la competitividad y la sustentabilidad han aumentado la demanda de recursos humanos calificados, por ello los principios centrales del sistema de patentes buscan fomentar simultáneamente la innovación y la competitividad mediante reglas justas para el mercado, con el objetivo de evitar comportamientos no deseados y abusos, lo que desconoce abiertamente la generalización de prácticas monopólicas de las empresas multinacionales. Las economías de los países centrales son las más exitosas en la atracción de talento: Estados Unidos es líder mundial como receptor de patentes; los resultados de solicitudes de patentes por oficina para no residentes de 2015-2019 reflejan su popularidad como el mercado más grande del mundo: recibió poco más del doble de solicitudes de extranjeros que China, país que ocupa la segunda posición, y 5.3 veces más que Japón, tres de las principales economías del mundo. En cuarto lugar se ubica Corea del Sur, le siguen en orden de importancia las oficinas de India, Canadá y Australia.

Los datos del periodo 2015-2019 respecto al correspondiente a los años 19802019 muestran que en términos relativos China recibió 33.9 por ciento (708 mil) del total de solicitudes emitidas por extranjeros, mientras que esa relación en el primer periodo fue de 25.2 por ciento (1.6 millones). A pesar de las diferencias absolutas dichos datos reflejan la popularidad que está ganando la oficina de China entre los inventores extranjeros. En ese orden de ideas, las oficinas de Brasil y México en el nivel mundial ocupan la octava y décima posición respectivamente, pero en Latinoamérica se ubican en la primera y segunda posición, seguidas de Argentina, Colombia y Perú. Este resultado es paradójico en el caso de México, ya que 45.8 por ciento de sus inventores busca patentar fuera del país y su tasa de inmigración asciende a 92 por ciento (cuadro 5).

\section{Países líderes en la emisión de solicitudes de patentes por origen nacional}

Los datos de patentes constituyen un indicador inigualable para estudiar una serie de fenómenos relacionados con la innovación y la movilidad de inventores; esos datos se asocian con una clase específica y más homogénea de trabajadores altamente calificados que la que se obtiene cuando se clasifican por nivel de escolaridad (WIPO, 2013). En el apartado de métodos y datos se expresa que la información PCT proporciona la nacionalidad y país de residencia del 
inventor, al menos uno de ellos. Esta información permite conocer qué países son líderes en inventores nacionales, quiénes tienen la diáspora más grande que busca patentar en una oficina extranjera y cuáles son líderes en inventores nacionales que quieren patentar en la oficina de su país. En el periodo 2015-2019 China fue el líder mundial en la emisión de patentes por nacionales (con más de 6 millones), le siguen los nacionales de Estados Unidos (1.4 millones), Japón (1.3 millones) y Corea del Sur (800 mil). Los chinos solicitaron patentar 2.4 veces más que los estadounidenses, 2.8 veces más que los japoneses y 5.4 veces más que los coreanos. Con una brecha notable le siguen Alemania y Francia; mientras que Brasil se colocó en la posición 24 y México en la 33, los brasileños emitieron 2.8 veces más solicitudes que los mexicanos, 3.8 veces más en la oficina de origen y su diáspora emitió 1.7 veces más que la diáspora mexicana. A diferencia del resto, China cuenta con una diáspora de apenas 4.8 por ciento. En términos relativos los países con la proporción más alta de inventores nacionales que patentan en una oficina extranjera son: México (45.8 por ciento), Estados Unidos (44.6 por ciento), Japón (44.1 por ciento), Alemania (58.8 por ciento), Corea del Sur (30.1 por ciento) y Brasil (27.5 por ciento). En términos absolutos Estados Unidos y Japón tienen la diáspora más grande, más de 1 millón de inventores emitieron una solicitud en una oficina extranjera entre 2015-2019, respectivamente (cuadro 5).

\section{CUADRO 5}

Oficinas líderes en atracción de inventores en el nivel mundial y de países latinoamericanos en los periodos 1980-2019 y 2015-2019

Solicitudes de patentes

\begin{tabular}{|c|c|c|c|c|}
\hline & Inmigrantes (A) & $\begin{array}{c}\% \text { Inmigrantes } \\
\text { respecto de A }\end{array}$ & $\%$ Residentes & \% Diáspora \\
\hline & 1980-2019 & 2015-2019 & \multicolumn{2}{|c|}{ 2015-2019 } \\
\hline \multicolumn{5}{|c|}{ Oficina-Mundo } \\
\hline Estados Unidos & 6244034 & 25.2 & 47.9 & 44.6 \\
\hline China & 2087130 & 33.9 & 89.5 & 4.8 \\
\hline Japón & 1687003 & 17.7 & 81.1 & 44.1 \\
\hline Corea del Sur & 1077113 & 21.6 & 78.0 & 30.1 \\
\hline India & 564510 & 29.1 & 31.7 & 46.1 \\
\hline Canadá & 1171665 & 13.5 & 11.7 & 82.8 \\
\hline Australia & 589735 & 22.5 & 8.8 & 78.5 \\
\hline
\end{tabular}




\begin{tabular}{|c|c|c|c|c|}
\hline & Inmigrantes (A) & $\begin{array}{c}\% \text { Inmigrantes } \\
\text { respecto de A }\end{array}$ & $\%$ Residentes & \% Diáspora \\
\hline & $1980-2019$ & 2015-2019 & \multicolumn{2}{|c|}{ 2015-2019 } \\
\hline Brasil & 506945 & 21.4 & 19.2 & 27.5 \\
\hline Alemania & 510612 & 19.8 & 70.1 & 58.8 \\
\hline México & 401104 & 19.5 & 8.1 & 45.8 \\
\hline \multicolumn{5}{|c|}{ Oficina-Latinoamérica } \\
\hline Brasil & 506945 & 21.4 & 19.2 & 27.5 \\
\hline México & 401104 & 19.5 & 8.1 & 45.8 \\
\hline Argentina & 130589 & 12.3 & 14.3 & 38.4 \\
\hline Colombia & 46200 & 19.3 & 20.5 & 31.7 \\
\hline Perú & 26423 & 21.4 & 7.6 & 38.4 \\
\hline Costa Rica & 10879 & 23.5 & 2.6 & 84.2 \\
\hline Ecuador & 11979 & 16.6 & 6.8 & 30.4 \\
\hline Venezuela & 53603 & 3.4 & 8.9 & 50.1 \\
\hline Panamá & 5595 & 32.2 & 13.6 & 45.7 \\
\hline Guatemala & 8057 & 16.6 & 1.9 & 77.0 \\
\hline
\end{tabular}

Lideres mundiales y latinoamericanos en patentes otorgadas (inventores)

El panorama observado cambia al analizar las patentes otorgadas, aquellas invenciones que son protegidas por la ley y que cumplieron con las características de una invención para ser patentada; es decir, la invención no fue evidente para un experto en la materia, lo que significa que el experto no llegó al mismo resultado, no fue objeto de uso público ni conocida por terceros, ya sea en la presentación de la solicitud o en su creación, y se cumplió con los requisitos administrativos y pagos correspondientes.

Según Gonzalez y Rasagam (2015) las principales economías innovadoras valoran la calidad de sus instituciones, sus entornos políticos estables y un entorno regulatorio y empresarial eficaz. Dichas economías han desarrollado políticas abiertas en las que el crecimiento y la gestión del talento son centrales y prioritarias para la apertura de la competitividad, atraer y retener el talento y formar capital humano altamente calificado. Las patentes permiten la difusión de nuevos conocimientos y ayudan a la transferencia y comercialización de tecnologías y desempeñan un papel crucial en la reducción de costos de transacción 
en la concesión de licencias, así como en la estimulación del crecimiento económico. Tal enfoque, de orientación institucionalista, omite el papel de las grandes corporaciones en la definición de la agenda de investigación y desarrollo tecnológico y científico de los países subdesarrollados.

A escala mundial se otorgaron 6.9 millones de patentes durante 2015-2019, 56.5 por ciento se aprobó en oficinas de países asiáticos y 24.6 por ciento en América del Norte; los tenedores de esas patentes son principalmente de China (30.0 por ciento) y Estados Unidos (22.9 por ciento). México se coloca en la posición 11 con 0.9 por ciento de las patentes otorgadas y Brasil en la posición 13 con 0.5 por ciento. Los datos correspondientes a las patentes otorgadas corroboran que, en efecto, China es el país con el mayor número de inventores y patentes, dicha posición se consolida por la inventiva nacional, pues sólo 22.7 por ciento de las patentes fue para no residentes. Mientras que la oficina de Estados Unidos tiene el mayor número de inventores no residentes, de manera que se consolida como la más atractiva para los inventores extranjeros (quienes aportan 52.8 por ciento de las patentes) y agrupa 31.2 por ciento del total de las patentes.

Brasil se coloca en mejor posición que México en la emisión de solicitudes de patentes, pero en materia de patentes otorgadas México logra un mejor lugar: se ubica en la posición 11, pero 95.2 por ciento de las patentes corresponde a no residentes; en tanto, Brasil aparece en el lugar 13 con 89.2 por ciento. Ambas naciones muestran una alta dependencia de la inventiva extranjera a fin de mantener su posición. México agrupa 1.6 por ciento de las patentes y Brasil 1.1 por ciento (cuadro 5).

En el periodo 2015-2019 se otorgaron 7.2 millones de patentes por origen del inventor, casi 3 millones de inventores patentaron en el exterior. China, Estados Unidos, Japón y Corea del Sur son los países con el mayor número de patentes logradas por nacionales, grupo que observa diferencias importantes respecto a su diáspora. Los chinos tienen 24.0 por ciento de las patentes y su tasa de emigración es de 7.6 por ciento, la más baja entre los países en estudio; asimismo, ocupa la sexta posición, en términos absolutos, entre los países con la mayor diáspora de inventores. Los estadounidenses tienen 19.7 por ciento de las patentes y una tasa de emigración de 47.3 por ciento; además es el país que más inventores extranjeros atrae y paradójicamente el que tiene en términos absolutos la primera posición con la mayor diáspora; en segundo lugar se encuentra Japón con casi 657 mil inventores, seguido de Alemania con 344 mil y Corea del Sur con 201 mil. Una brecha enorme separa a los brasileños y mexicanos de los estadounidenses, 
japoneses, coreanos y chinos, por sus tasas más altas de emigración: Brasil con 55.7 por ciento y México con 59.4 por ciento. Adicionalmente, México se ubica en la posición 29 y Brasil en la 35 en la clasificación de los países con la mayor diáspora de inventores (cuadro 6).

\section{CUADRO 6}

Patentes otorgadas por origen (2015-2019). Posición, distribución porcentual y porcentaje de patentes otorgadas a nacionales en el extranjero

\begin{tabular}{|c|c|c|c|c|c|c|c|}
\hline $\begin{array}{l}\text { País- } \\
\text { origen }\end{array}$ & $\begin{array}{l}\text { Patentes } \\
\text { del periodo } \\
\text { por origen }\end{array}$ & $\begin{array}{l}\text { Participación } \\
\text { porcentual }\end{array}$ & $\begin{array}{c}\text { Tasa de } \\
\text { emigración }\end{array}$ & Ranking & $\begin{array}{c}\text { Inventores } \\
\text { en el } \\
\text { extranjero }\end{array}$ & $\begin{array}{c}\text { Participación } \\
\text { porcentual }\end{array}$ & $\begin{array}{c}\text { Posición } \\
\text { inventores } \\
\text { en el } \\
\text { extranjero }\end{array}$ \\
\hline \multicolumn{8}{|c|}{$2015-2019$} \\
\hline Mundo & 7203065 & $100.0 \%$ & & & 2990708 & $100.0 \%$ & \\
\hline China & 1731774 & $24.0 \%$ & $7.6 \%$ & 1 & 671471 & $22.5 \%$ & 1 \\
\hline $\begin{array}{l}\text { Estados } \\
\text { Unidos }\end{array}$ & 1418640 & $19.7 \%$ & $47.3 \%$ & 2 & 132354 & $4.4 \%$ & 6 \\
\hline Japón & 1414361 & $19.6 \%$ & $46.4 \%$ & 3 & 656820 & $22.0 \%$ & 2 \\
\hline $\begin{array}{l}\text { Corea } \\
\text { del Sur }\end{array}$ & 634694 & $8.8 \%$ & $31.7 \%$ & 4 & 201049 & $6.7 \%$ & 4 \\
\hline Brasil & 8306 & $0.1 \%$ & $55.7 \%$ & 30 & 3122 & $0.1 \%$ & 35 \\
\hline México & 5257 & $0.1 \%$ & $59.4 \%$ & 37 & 4627 & $0.2 \%$ & 29 \\
\hline \multicolumn{8}{|c|}{ Países con mayor diáspora de inventores } \\
\hline & $\begin{array}{l}\text { Estados } \\
\text { Unidos }\end{array}$ & Japón & Alemania & $\begin{array}{l}\text { Corea } \\
\text { del Sur }\end{array}$ & Francia & China & \\
\hline
\end{tabular}

Fuente: estimación propia con datos WIPO, 1985-2019.

Un dato relevante es que China y Brasil ostentan el porcentaje más bajo de solicitudes aprobadas por oficina y por origen nacional. Si bien China tiene un número muy alto de solicitudes su tasa de éxito es baja, mientras que la tasa de éxito de Estados Unidos es de 20 por ciento aproximadamente, con un número considerablemente más bajo de solicitudes. Lim (2016) explica que el volumen de aplicaciones de China puede no representar con precisión un aumento en su nivel de innovación tecnológica, puesto que la mayoría de las patentes se otorga a innovaciones menos valiosas con un poder de permanencia limitado, en comparación con las que se otorgan en economías centrales con una vida útil más larga. Ello sugiere que el impacto de las patentes chinas es limitado en la innovación global o que existen menores barreras de entrada en términos de tecnología y 
capital. Adicionalmente, las patentes pueden estar incentivadas por políticas gubernamentales que privilegian la cantidad sobre la calidad mediante subsidios y bonificaciones, incentivos que se filtran en empresas como Huawei, que ofrecen bonificaciones relacionadas con las patentes a sus empleados.

Si se aplica la reflexión de Lim (2016) para México, el hecho de que los mexicanos busquen con mayor frecuencia patentar sus invenciones en el exterior y tengan más éxito en el extranjero (la tasa de éxito de aquellos que patentan en el país equivale a 31.1 por ciento, contra 53.8 por ciento entre los que patentan en el exterior) podría ser reflejo de: 1. Las patentes de mexicanos están cumpliendo con los estándares internacionales. 2. Los inventores mexicanos tienen ambiciones de mercado más allá del ámbito nacional. 3. Indica el valor relativo de la patente mexicana y su impacto a escala global.

En ese sentido, quedan ciertas incógnitas: ¿el bajo éxito de la oficina de México podría ser un incentivo para buscar patentar fuera? y ¿a qué se debe el bajo éxito de patentes de los mexicanos en el país? ¿Alguna explicación análoga encontrada para los inventores chinos cabría para los inventores mexicanos? Las explicaciones posibles son: falta de mejoras tecnológicas en las patentes, falta de calidad de las patentes, o bien, que México no ha alcanzado el nivel de innovación de otras economías líderes capaz de atraer el interés empresarial y acceder a apoyos económicos. Brasil, por ejemplo, posee un sistema de patentes más consolidado y el interés empresarial. Es probable que el nivel de intervención gubernamental justifique las diferencias a favor de China y Brasil y no únicamente se atribuyan a falta de interés del capital privado.

La falta de recursos suficientes para la protección de la propiedad intelectual en México es uno de los principales obstáculos que seguirá dificultando la protección intelectual. Cabe resaltar que sólo 4.8 por ciento de las patentes fue para mexicanos y el resto para no residentes; en contraste, la tasa de éxito de los inventores mexicanos en el exterior (53.8 por ciento) es similar a la de los inventores inmigrantes en México (53.7 por ciento) (cuadro 7). 


\section{CUADRO 7}

Indicadores seleccionados sobre patentes aprobadas para el periodo 2015-2019. Los cuatro líderes mundiales y los dos líderes latinoamericanos con patentes aprobadas

\begin{tabular}{lcccccc}
$\quad \begin{array}{c}\text { Porcentaje } \\
\text { patentes aprobadas }\end{array}$ & China & $\begin{array}{c}\text { Estados } \\
\text { Unidos }\end{array}$ & Japón & $\begin{array}{c}\text { Corea } \\
\text { del Sur }\end{array}$ & Brasil & México \\
\hline Total por oficina & $30.6 \%$ & $52.4 \%$ & $61.3 \%$ & $54.5 \%$ & $25.3 \%$ & $51.9 \%$ \\
Total por origen & $27.2 \%$ & $54.3 \%$ & $61.8 \%$ & $53.8 \%$ & $23.4 \%$ & $41.5 \%$ \\
Residentes en la oficina & $77.3 \%$ & $47.2 \%$ & $78.4 \%$ & $75.3 \%$ & $10.8 \%$ & $4.8 \%$ \\
Residentes-origen & $26.4 \%$ & $51.6 \%$ & $59.3 \%$ & $52.6 \%$ & $14.3 \%$ & $31.1 \%$ \\
Inmigrantes & $66.2 \%$ & $53.1 \%$ & $69.9 \%$ & $61.3 \%$ & $27.9 \%$ & $53.7 \%$ \\
Emigrantes & $43.3 \%$ & $57.5 \%$ & $65.1 \%$ & $56.6 \%$ & $47.2 \%$ & $53.8 \%$ \\
\hline
\end{tabular}

Fuente: estimación propia con datos de WIPO, 2015-2019.

\section{GRÁFICA 4}

Cargos por el uso de propiedad intelectual, pagos

(balanza de pagos a precios actuales, millones de dólares), 1990-2019

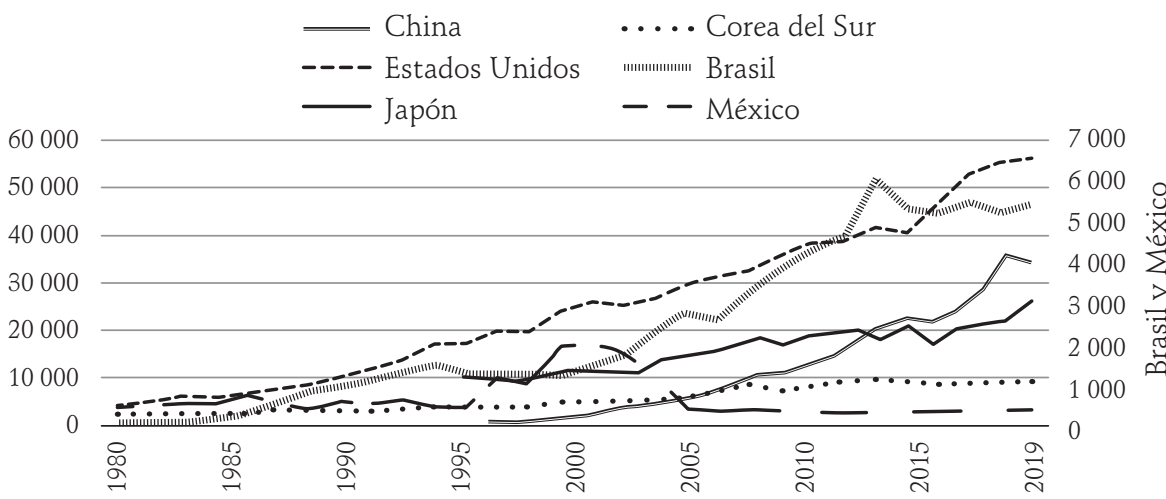

Fuente: elaboración propia con datos de Banco Mundial, 2020.

Los resultados estadísticos muestran que Estados Unidos es, por mucho, el país que obtiene los mayores beneficios por el cobro de regalías de parte de las entidades cuya propiedad intelectual es utilizada por terceros: en 2018 recibió 1.7 veces más que China, 2.2 veces más que Japón, 5.7 veces más que Corea del Sur, 10.7 más que Brasil y 182.1 veces más que México. Entre los países latinoamericanos México percibió un monto por regalías 17 veces menor a Brasil y mostró una tendencia lineal de 2008 a 2019, mientras que Brasil tuvo una tendencia creciente 
(gráfica 4). Esa gran brecha en las ganancias por el cobro de regalías se debe, de acuerdo con las Naciones Unidas (2019), a varias acciones emprendidas por Brasil: una mayor inversión en investigación y desarrollo, calidad de las publicaciones científicas y las universidades, las empresas invierten en las áreas que patentan; además, es el único país latinoamericano que cuenta con polos de ciencia y tecnología clasificados entre los 100 primeros del mundo. Por otro lado, su tasa de emigración y dependencia de la inventiva extranjera es menor que la de México.

\section{Conclusiones}

A pesar de que la oficina de México se encuentra entre las primeras 20 en el mundo con el mayor número de solicitudes de patentes y es la segunda más importante en América Latina, la posición que ocupa se debe a solicitudes de extranjeros; su lugar se modifica al tomar en cuenta el origen del inventor o del solicitante de derechos: los inventores mexicanos ocupan la posición 32 y casi uno de cada dos busca patentar sus invenciones en el exterior. La tasa de éxito es más alta para los no residentes y los mexicanos en el exterior: sólo 4.8 por ciento de las patentes son de inventores mexicanos que se dirigen a la oficina de México. Tales resultados confirman lo referido por Guadarrama (2018) acerca de los países con alta innovación e inversión en investigación y desarrollo como Estados Unidos, Corea del Sur y Finlandia, donde el progreso científico es impulsado y apoyado por fondos gubernamentales y de empresas privadas, al tiempo que la innovación ha impulsado el crecimiento económico y la creación de empleos. Las economías centrales basadas en el conocimiento promueven estrategias para la formación de una fuerza laboral altamente calificada y así aumentar los flujos de conocimiento entre empresas, universidades y centros públicos y privados de investigación.

Estados Unidos, China, Japón y Corea del Sur son economías que destinan recursos en activos intangibles y para garantizar los derechos de propiedad intelectual, con ello han transformado los activos intangibles en activos económicos comercializables (WIPO, 2019). En países como México a las pequeñas y medianas empresas (pymes), aunque cuenten con propiedad intelectual, les resulta difícil encontrar financiamiento que les permita el desarrollo de activos intangibles, porque esas empresas no representan una garantía de activos crediticios para los bancos. 
En México, en 2016, tan sólo se invirtió 0.1 por ciento del gasto público en investigación y desarrollo como proporción del PIB, 3.8 por ciento de las empresas llevó a cabo actividades de investigación y desarrollo tecnológico y 8.3 por ciento de las empresas realizaron proyectos de innovación (INEGI, 2021). Estos resultados respaldan la conclusión de Guadarrama (2018) en cuanto a que no se ha hecho lo suficiente para estimular la innovación y el desarrollo científico y tecnológico en México; lo que ha prevalecido son presupuestos insuficientes, reducción del gasto y escasa inversión privada y pública, rasgos de la implantación de las políticas neoliberales de restricción del gasto público, prevalecientes desde los 1980. Lo que se requiere, "es un ritmo incremental y estable de inversión» en investigación y desarrollo científico y tecnológico, constante formación de capital humano y mayor participación de empresas privadas, así como de una constante vinculación empresarial con universidades y centros de investigación.

México es un expulsor neto de migrantes calificados y altamente calificados hacia Estados Unidos, paradójicamente en materia de patentes exhibe una alta dependencia de la innovación de extranjeros, sobre todo nacidos en ese país, lo cual resulta incomprensible si se considera que la oficina de México se encuentra entre las más atractivas para los inventores extranjeros. Ese comportamiento invita a reflexionar o indagar en torno del escaso éxito de los mexicanos con la finalidad de patentar sus invenciones en México, y si ese reducido éxito resulta ser un incentivo para buscar patentar fuera del país.

Un tema pendiente de esta investigación es el análisis de los sectores en que innovan los mexicanos tanto en el país como en el exterior, ya que ello puede dar una idea del éxito del patentamiento fuera del país, ya que los sectores en que patentan revisten especial relevancia en el desarrollo económico de los países de destino en que patentan sus invenciones, cuyos ostensibles beneficios quedan en manos de las grandes corporaciones multinacionales mediante la concentración de patentes (Delgado, 2020).

México tiene el potencial para incursionar en la sociedad del conocimiento, por lo que debe redoblar esfuerzos con el propósito de alcanzar un sistema de patentes más sólido y mantener al menos los estándares de la oficina de Brasil, al mismo tiempo que impulsa la innovación y el desarrollo tecnológico y conserva su posición entre las 20 oficinas más atractivas en el mundo y entre los países latinoamericanos, no sólo para inventores extranjeros sino también para sus nacionales, en un balance entre inmigrantes y emigrantes (como sucede con la oficina de Estados Unidos). De lo contrario seguirá perdiendo competitividad 
frente a otras economías, a la vez que afianzará su dependencia a la innovación de extranjeros y motivará a su capital humano altamente calificado a formar parte de su creciente diáspora. Dicha situación, lejos de contribuir al desarrollo del país, está dando lugar a nuevas modalidades de intercambio desigual y fortalece las ya existentes (Delgado, 2020).

La situación de las oficinas de patentamiento de México y Brasil revela, en general, el papel de las empresas de los países subdesarrollados, donde sus nacionales encuentran pocos incentivos para patentar por el hecho de que sus innovaciones son de escaso valor de mercado. Los no residentes protegen sus innovaciones con la finalidad de evitar su uso no rentable en todos los países donde se comercializan o licencian sus productos. Dicha tendencia, como se ha anotado en este trabajo, ha sido más acusada en el periodo neoliberal por el propio proceso de marginación del Estado en la protección de los capitalistas locales y los incentivos para que las corporaciones multinacionales amplíen su presencia, lo que se ha reforzado con la puesta en marcha de los acuerdos comerciales firmados por el gobierno mexicano.

El impacto profundamente recesivo de las políticas neoliberales ha sido el estímulo primordial para impulsar la migración masiva de fuerza de trabajo altamente calificada: el intercambio desigual expresado en la exportación de materias primas y de mano de obra barata ahora se manifiesta en la expulsión de profesionistas, tecnólogos y científicos, quienes al estar dispuestos a recibir salarios inferiores a los que perciben sus similares nativos en el exterior propician una reforzada transferencia de valor que se incrementa cuando el país compra los productos que sus propios creadores idean y desarrollan. Esta es la nueva paradoja del subdesarrollo: se exporta fuerza de trabajo educada en México y se compra el producto de su trabajo al adquirir las innovaciones que esa fuerza de trabajo permite patentar.

\section{Referencias}

Bahar, D., Choudhury, P. y Rapoport, H. (2019). Migrant inventors and the technological advantage of nations. Recuperado de https://papers.ssrn.com/sol3/papers.cfm ?abstract_id $=3409136$ 
Breschi, S., Lissoni, F. y Tarasconi, G. (2014). «Inventor data for research on migration and innovation: a survey and a pilot». Econpapers. Recuperado de https://econ papers.repec.org/paper/wipwpaper/17.htm

Comisión sobre Derechos de Propiedad Intelectual (2002). Integrando los derechos de propiedad intelectual y la politica de desarrollo. Informe de la Comisión sobre Derechos de Propiedad Intelectual. Recuperado de http://www.iprcommission.org/papers/pdfs/Multi_ Lingual_Documents/Multi_Lingual_Main_Report/DFID_Main_Report_Spanish _RR.pdf

Comisión Europea (1995). Libro Verde de la Innovación (volumen 1). Bruselas: Comisión Europea. Recuperado de https://eur-lex.europa.eu/resource.html?uri=cellar: eb5dae41-104d-4724-ac99-d7cbcfa11b86.0008.01/DOC_18format=PDF

Correa, C. (2018). "The myth of IP incentives for all nations». Intellectual Property Watch. Recuperado de https://www.ip-watch.org/2018/08/09/el-mito-de-los-incentivos -en-materia-de-propiedad-intelectual-para-todas-las-naciones-preguntas-yrespuestas-con-carlos-correa/

China Power Team (15 de febrero de 2016). "Are patents indicative of Chinese innovation?» China Power. Recuperado de https://chinapower.csis.org/patents/

Delgado Wise, R. (2020). «Reflexiones en torno a la reestructuración de los sistemas de innovación en el horizonte Norte-Sur. Lecciones a partir de la experiencia mexicana». En Bialakowsky, A.L., Bukstein, G. y Montelongo, L.M. (comps.), Intelecto social, procesos laborales y saber colectivo. Recuperado de https://www.teseopress. $\mathrm{com} /$ intelectosocial/chapter/reflexiones-en-torno-a-la-reestructuracion-de-los -sistemas-de-innovacion-en-el-horizonte-norte-sur-lecciones-a-partir-de-laexperiencia-mexicana-4/

Diario Oficial de la Federación (DOF) (26 de abril de 2018). «Acuerdo por el que se modifica el diverso por el que se da a conocer la tarifa por los servicios que presta el Instituto Mexicano de la Propiedad Industrial». Recuperado de https://www.dof.gob. $\mathrm{mx} /$ nota_detalle.php?codigo $=5520840 \& \mathrm{fech} a=26 / 04 / 2018 \&$ print $=$ true

Fink, C. (2013). «What leads inventor to migrate?». World Economic Forum. Recuperado de https://www.weforum.org/agenda/2013/07/what-leads-inventors -to-migrate/

Gobierno de México (s/f). "Capítulo 20. Derechos de propiedad intelectual». Recuperado de https://www.gob.mx/cms/uploads/attachment/file/465802/20ESPDerech osdePropiedadIntelectual.pdf

Gold, E.R., Morin, J.F. y Shadeed, E. (31 de mayo de 2017). «Does intellectual property lead to economic growth? Insights from an improved IP dataset». Regulation \& Governance. Recuperado de https://papers.ssrn.com/sol3/papers.cfm?abstract_id=2978025 
Gonzalez y Rasagam, G. (8 de septiembre de 2015). «5 ways to close the global innovation divide». Banco Mundial. Recuperado de https://blogs.worldbank.org/ voices/5-ways-close-global-innovation-divide

Guadarrama Atrizco, V.H. (2018). «Inversión para ciencia, tecnología e innovación en México». INCYTU (11). Recuperado de http://www.foroconsultivo.org.mx/FCCyT/ incytu/11.pdf

Gurría, Á. (2010). «La innovación: piedra de toque del desarrollo mexicano». OECD. Recuperado de https://www.oecd.org/mexico/lainnovacionpiedradetoquedel desarrollomexicano.htm

Instituto Mexicano de la Propiedad Intelectual (IMPI) (2011). «Guía del usuario. Patentes y modelos de utilidad. Recuperado de https://www.cibnor.gob.mx/images/ stories/covisti/ott_cepat/guia_de_patentes.pdf

Instituto Mexicano de la Propiedad Intelectual (IMPI) (2020). Acuerdo histórico MéxicoEstados Unidos en materia de patentes. Recuperado de https://www.gob.mx/impi/ prensa/acuerdo-historico-mexico-estados-unidos-en-materia-de-patentes -233222?idiom $=$ es

Instituto Mexicano de la Propiedad Intelectual (IMPI) y Secretaría de Economía (SE). "Guía del usuario. Tratado de Cooperación en materia de patentes». Recuperado de https://www.gob.mx/cms/uploads/attachment/file/54266/GDU_PCT.pdf

Instituto Nacional de Estadística y Geografía (INEGI) (2021). «Información general». Recuperado de https://www.inegi.org.mx/temas/ciencia/\#Informacion_general

Kalanje, M. (s/f). "Role of intellectual property in innovation and new product development. Consultant, SMEs Division». WIPO. Recuperado de https://www. wipo.int/export/sites/www/sme/en/documents/pdf/ip_innovation_development. pdf

Lim, E. (15 de febrero de 2016). «Are patents indicative of Chinese innovation?. China Power Team. Recuperado de https://chinapower.csis.org/patents/

Mazzoleni, R. y Nelson, R.R. (1998). «Economic theories about the benefits and costs of patents». Journal of Economic Issues, 32(4). Recuperado de http://gesd.free.fr/ mazzo98.pdf

Méndez Cruz, R.J. (2014). «Las patentes en méxico a 20 años de la adopción del acuerdo sobre aspectos de propiedad intelectual relacionados con el comercio (ADPIC)». XIX Congreso Internacional de Contaduría, Administración e Informática. Recuperado de http://congreso.investiga.fca.unam.mx/docs/xix/docs/2.10.pdf

Miguélez, E. y Fink, Carsten (mayo de 2013). «Measuring the international mobility of inventors: a new databse». WIPO Economics \& Statistics Series. Recuperado de https:// 
books.google.com.mx/books?hl=es\&lr=\&id=psGiDwAAQBAJ\&oi=fnd\&pg =PP1 $\& \mathrm{dq}=$ Migu\%C3\%A9lez+y+Fink+2013\&ots=-AhUqNtTnk\&sig=oXwO32Dlalggz pwJG0XcSKK9a1g\#v=onepage \&q=Migu\%C3\%A9lez\%20y\%20Fink\%202013\& $\mathrm{f}=$ false

Organización de las Naciones Unidas (2019). «Noticias ONU, América Latina avanza lentamente en el terreno de la innovación». Recuperado de https://news.un.org/ es/story/2019/07 /1459671

Ozden, C. (2017). "Global talent flows: causes and consequences of high-skilled migration». World Bank Blogs. Recuperado de https://blogs.worldbank.org/develop menttalk/global-talent-flows-causes-and-consequences-high-skilled-migration

Shapiro, J. y Hassett, A. (2005). «What ideas are worth: the value of intellectual capital and intangible assets in the American economy». Sonecon. Recuperado de https:// www.sonecon.com/docs/studies/Value_of_Intellectual_Capital_in_American_ Economy.pdf

Sistema de Información sobre Comercio Exterior (SICE). «Tratado de Libre Comercio de América del Norte». Recuperado de http://www.sice.oas.org/Trade/nafta_s/ CAP17_2.asp

United States Patent and Trademark Office (USPTO) (2019). «Report to Congress pursuant to P.L. 115-273, the SUCCESS Act.». Recuperado de https://www.uspto.gov/ sites/default/files/documents/USPTOSuccessAct.pdf

World Intelectual Property Organization (WIPO) (s/f). «Notification no. 39. Convention establishing the World Intellectual Property Organization». Recuperado de https:// www.wipo.int/treaties/en/notifications/convention/treaty_convention_39.html

World Intelectual Property Organization (WIPO) (s/f). «World Intelectual Property Organization». Recuperado de https://www.wipo.int/portal/en/index.html

World Intelectual Property Organization (WIPO) (s/f). «Tratados y partes contratantes». Recuperado de https://www.wipo.int/treaties/es/remarks.jsp?cnty_id=275C

World Intelectual Property Organization (WIPO) (s/fa). «Preguntas frecuentes: patentes. Conceptos básicos». Recuperado de https://www.wipo.int/patents/es/faq_ patents.html

World Intelectual Property Organization (WIPO) (s/fb). «El negocio de la propiedad intelectual». Recuperado de https://www.wipo.int/ipadvantage/es/articles/ article_0088.html

World Intelectual Property Organization (WIPO) (2013). «Special section the international mobility of inventors. The international mobility of inventors». Recuperado de https://www.wipo.int/edocs/pubdocs/en/wipo_pub_941_2013-section1.pdf 
World Intelectual Property Organization (WIPO) (2019). «The global innovation index 2019. Chapter 1». Recuperado de https://www.wipo.int/edocs/pubdocs/en/ wipo_pub_gii_2019-chapterla.pdf

Zavodny, M. (2011). «Immigration and American jobs». American Enterprise Institute. Recuperado de https://www.aei.org/wp-content/uploads/2011/12/-immigrationand-american-jobs_144002688962.pdf?x91208 